Artigo

\title{
Estágio curricular no Ensino Remoto: concepções e percepções dos professores em formação inicial
}

\author{
Curricular internship in Remote Education: conceptions and perceptions of teachers in \\ initial training \\ Pasantía curricular en Educación Remota: concepciones y percepciones de los \\ docentes em formación inicial
}

\author{
Carla Denize Ott Felcher ${ }^{1}$ \\ [0000-0002-9733-9451] \\ Daniel Keglis de Sousa² \\ [0000-0002-5471-3546]
}

\section{Resumo}

O presente artigo tem por objetivo apresentar e analisar as concepções e percepções de professores em formação inicial sobre a realização de um estágio no ensino remoto, considerando que o estágio curricular tem caráter obrigatório e prepara o acadêmico para o exercício da docência. Com a paralisação das aulas presenciais em decorrência da pandemia causada pelo COVID-19, os estágios curriculares ficaram suspensos até a publicação do Parecer no 5/2020 do Conselho Nacional de Educação, o qual possibilitou a retomada das atividades educacionais, em todos os âmbitos, através do formato de ensino remoto. A metodologia adotada foi predominantemente qualitativa e a produção de dados foi proveniente de um questionário online respondido por treze estagiários e interpretados sob a ótica da análise de conteúdo. Os resultados indicam que as concepções prévias apresentadas pela maioria dos estagiários não foram positivas, inclusive alguns pensaram em desistir do estágio neste formato. Após a finalização do estágio no ensino remoto, os participantes da pesquisa apresentaram percepções positivas, considerando que foi uma experiência produtiva e de grandes aprendizagens. As tecnologias digitais receberam destaque entre os resultados, uma vez que, foram apontadas como relacionadas às aprendizagens construídas, mas também como dificuldades, no que diz respeito ao emprego nos processos de ensino e aprendizagem. É essencial investimentos na formação de professores para um uso inteligente das tecnologias digitais, visto que, o cenário educacional é incerto, mas, não pode parar.

Palavras-chave: Ensino Remoto. Estágio Curricular. Concepções. Percepções.

\begin{abstract}
\footnotetext{
${ }^{1}$ carla.felcher@ufpel.edu.br, Professora IFM - UFPel, Pelotas/RS/Brasil.

${ }^{2}$ danielkeglisead@gmail.com, Professor CLMD - UAB - UFPel, Pelotas/RS/Brasil.
}

This article aims to present and analyze the conceptions and perceptions of teachers in initial training on the realization of an internship in remote education, considering that the curricular internship is mandatory and prepares the academic for teaching. With the interruption of the face-to-face classes due to the pandemic caused by COVID-19, the curricular internships were suspended until the publication of Opinion no 5/2020 of the National Council of Education, which allowed the resumption of educational activities, in all areas, through the remote teaching format. The methodology adopted was predominantly qualitative and the production of data came from an online questionnaire answered by thirteen interns and interpreted from the perspective of content analysis. The results 
indicate that the previous conceptions presented by the majority of the interns were not positive, even some thought about giving up the internship in this format. After completing the internship in remote education, the research participants showed positive perceptions, considering that it was a productive experience and of great learning. Digital technologies received prominence among the results, since they were pointed out as related to the constructed learning, but also as difficulties, with regard to employment in the teaching and learning processes. Investments in teacher training are essential for the intelligent use of digital technologies, since the educational scenario it is uncertain, but, it cannot stop.

Keywords: Remote Education. Curricular stage. Conceptions. Perceptions.

\section{Resumen}

Este artículo tiene como objetivo presentar y analizar las concepciones y percepciones de docentes em formación inicial sobre la realización de una pasantía en educación remota, considerando que la pasantía curricular es obligatoria y prepara al académico para la docencia. Con la interrupción de las clases presenciales por la pandemia provocada por el COVID-19, se suspendieron las pasantías curriculares hasta la publicación del Dictamen no 5/2020 del Consejo Nacional de Educación, que permitió reanudar las actividades educativas, en todos los ámbitos a través del formato de enseñanza remota. La metodología adoptada fue predominantemente cualitativa y la producción de datos provino de um cuestionario en línea respondido por trece pasantes e interpretado desde la perspectiva del análisis de contenido. Los resultados indican que las concepciones previas presentadas por la mayoría de los pasantes no fueron positivas, incluso algunos pensaron en abandonar la pasantía en este formato. Tras finalizar la pasantía en educación remota, los participantes de la investigación mostraron percepciones positivas, considerando que fue una experiencia productiva y de gran aprendizaje. Las tecnologías digitales cobraron protagonismo entre los resultados, ya que se señalaron como relacionadas con el aprendizaje construido, pero también como dificultades, encuanto al empleo em los procesos de enseñanza y aprendizaje. Las inversiones em formación docente son fundamentales para el uso inteligente de las tecnologías digitales, ya que el escenario educativo es incierto, pero no puede detenerse.

Palabras claves: Educación remota. Pasantía curricular. Concepciones. Percepciones.

\section{Introdução}

A formação inicial é pauta de debates e pesquisas, configurando-se como um momento relevante na formação do professor. Nesse contexto, o estágio curricular do Curso de Licenciatura em Matemática a Distância (CLMD), de caráter obrigatório, tem por objetivo preparar o aluno para o exercício da docência. Esse curso requer a realização de quatro estágios, dois deles nos anos finais do Ensino Fundamental e dois no Ensino Médio. Cabe salientar que esta investigação tem como pano de fundo o desenvolvimento do Estágio Curricular Supervisionado III (ECS III), em Matemática, mais especificamente no Ensino Médio.

De acordo com as orientações para o estágio, o estagiário deve conhecer a escola parceira, conversar com professores e alunos, observar a turma a ser trabalhada, realizar a docência compartilhada e por fim, a regência de classe. Ao longo dessa prática o estagiário deve considerar as orientações do professor titular da turma e do orientador de estágio. Deve conhecer as normas da escola, e considerar outras informações que se façam necessárias. Porém, em 2020 com a pandemia do Coronavírus, uma crise sem precedentes se instalou, forçando as medidas de isolamento e distanciamento social como estratégias para enfrentamento dessa situação (SOUZA; FERREIRA, 2020). 
De imediato, ainda no mês de março de 2020, as instituições educacionais, tanto escolas de Educação Básica, como as Universidades, paralisaram as aulas presenciais, orientadas pela portaria no 343, publicada em 17 de março de 2020 pelo Ministério da Educação (BRASIL, 2020). No entanto, segundo Souza e Ferreira (2020), o direito à educação não pode ser perdido de vista, mesmo em contextos de ameaça à vida, porque, 0 desenvolvimento cognitivo e o sonho em concluir o ensino superior seriam abalados. Nesse sentido, em razão da pandemia da COVID-19, o Ministério da Educação (MEC), através do Conselho Nacional de Educação (CNE), emitiu o parecer CNE/CP no 5/2020 que teve como orientação reorganizar o calendário escolar e viabilizar as atividades não presenciais para fins de cumprimento da carga horária mínima anual.

Com o objetivo de atender esse parecer, bem como a qualidade da formação inicial do professor, o estágio curricular sofreu profundas alterações em sua organização e desenvolvimento. Desse modo, os estágios começaram a acontecer no modelo de Ensino Remoto (ER), em sete (7) semanas, duas (2) para a observação e docência compartilhada e cinco (5) semanas para a regência de classe. Uma das maiores alterações ocorridas refere-se à necessidade do professor orientador avaliar a prática do estagiário em aula, para tanto, foi solicitado a gravação de no mínimo duas (2) videoaulas de mais ou menos 15 minutos cada uma e um momento síncrono de mais ou menos 45 minutos.

O ER caracteriza-se como uma atividade educacional, promovida e desenvolvida com o objetivo de manter a educação escolar e acadêmica "vivas", durante esse período de pandemia. De acordo com Arruda (2020) e Joye, Moreira e Rocha (2020), o Ensino Remoto nada mais é do que uma alternativa encontrada de forma emergencial para substituir as aulas presenciais e impedir que ocorra um grave retrocesso no processo educacional e na aprendizagem de estudantes, que, por sua vez, ficariam um longo período sem atividades educacionais regulares (tendo em vista a impossibilidade de estabelecer um prazo para o fim da pandemia), além dos danos e prejuízos sociais causados principalmente nas famílias de baixa renda e a provável evasão escolar.

$\mathrm{Na}$ tentativa de compreender e avaliar o estágio curricular nessas condições e circunstâncias, o objetivo deste artigo é apresentar e analisar as concepções e percepções de professores em formação inicial sobre a realização de um estágio no ensino remoto. Esse estágio foi desenvolvido por treze (13) acadêmicos na rede pública estadual de um município do Sul do Rio Grande do Sul. De acordo com Matos e Jardilino (2020), concepção implica em um processo de formação de conceitos baseados em características comuns a determinados objetos; enquanto percepção é uma interpretação do mundo através das sensações de cada um, pois não se percebe o mundo diretamente, mas sim, como resultado da interpretação. Complementando, para Felcher e Folmer (2019) concepção é aquilo que a pessoa sabia ou pensava antes da experiência, enquanto a percepção remete à interpretação após a experiência.

\section{Referencial teórico}

Ser professor não tem sido uma tarefa fácil, nem atrativa. E ser professor de Matemática é um desafio ainda maior, visto que, segundo Fiorentini e Castro (2003), esse é o professor que mais recebe críticas. O contexto que envolve a docência contribui para a baixa procura de vagas nos cursos de licenciatura nas universidades brasileiras e também para o reduzido número de professores formados em Matemática e, destes, um número ainda menor que exerce a docência, segundo o Instituto Nacional Estudos e Pesquisas (2008). 
É indiscutível a importância e a necessidade do professor de Matemática, vivenciar o estágio curricular na formação inicial, momento que merece atenção especial. O estágio, conforme recomenda as Diretrizes Curriculares Nacionais (DCN), no que se refere ao planejamento e a execução das práticas, deve estar apoiado nas reflexões desenvolvidas e articuladas pelas disciplinas curriculares em seu conjunto (BRASIL, 2002). Portanto, todos os professores do curso são responsáveis pela formação dos futuros professores, e não apenas o orientador ou supervisor de estágio. Deste modo, a formação do professor deve "[...] ser fundamentalmente um espaço de construção coletiva de conhecimento sobre o ensino e a aprendizagem" (BRASIL, 2002, p. 36).

Para a maioria dos acadêmicos o primeiro contato com a sala de aula é o estágio, o qual representa a inserção do professor em formação no campo da prática profissional. A legislação brasileira (BRASIL, 1996), salienta que os Cursos de Licenciaturas têm como objetivo formar professores para atuar na Educação Básica, tendo como requisito obrigatório a realização de estágio curricular supervisionado. Segundo Brasil (2015, p. 12), “o estágio curricular supervisionado é componente obrigatório da organização curricular das licenciaturas, sendo uma atividade específica intrinsecamente articulada com a prática e com as demais atividades de trabalho acadêmico".

Assim, de acordo com Fiorentini e Castro (2003) a prática de ensino e o estágio supervisionado podem ser caracterizados como um momento especial do processo de formação do professor, visto que, é o momento em que ocorre de maneira mais efetiva a transição de aluno a professor. Nesse sentido, Valverde (2005) salienta que o estágio permite vivenciar a realidade da escola em toda a sua complexidade, funcionamento, rotina, organização e problemas, sendo um momento difícil e de tomada de decisões, o que necessita de constantes investigações. Desse modo, não rara às vezes, esse momento é de angústia, dúvida, receio, mas também, de troca, de experiências diversas e de aprendizagem.

Corroborando com a discussão, Araújo (2020) enfatiza que o estágio é um espaço de ensino e de apreensão da profissão docente com as inúmeras dificuldades, mudanças e lutas diárias implicadas no ser, exercer e construir a docência. Ainda, o contato gradativo e sistemático com o futuro campo de trabalho, possibilita ao professor em formação, reconhecer limites e potencialidades das práticas educativas observadas, analisar, construir e testar possíveis ações para remediar ou suprir as necessidades práticas com as quais entrará em contato em sua futura prática profissional (CYRINO; PASSERINI, 2009).

Segundo Araújo (2020) o estágio proporciona uma dinâmica em que, ao mesmo tempo em que os estudantes são inseridos no cotidiano escolar das redes de Educação Básica, provoca movimentos transformadores nessa realidade escolar e os leva a produzir conhecimento em um processo de formação mútua: profissionais da escola e estudantes dos cursos de licenciatura. Desse modo, o estágio curricular supervisionado, segundo Pimenta e Lima (2006) e Araújo (2020), é de extrema relevância nos cursos de licenciaturas, considerado como um componente curricular essencial para formação de professores.

É indiscutível a importância do estágio na formação do professor, porém, é preciso discutir sobre essa prática no ensino remoto. $O$ ensino remoto é o nome dado ao formato educacional implantado em 2020, ano que ficará lembrado por uma das maiores pandemias já ocorridas nos últimos tempos. A COVID-19, doença causado pelo novo coronavírus (SARSCoV-2), de fácil contágio e disseminação, se tornou uma das maiores epidemias da história, afetando países do mundo inteiro e trazendo preocupações diversas para a humanidade. 
A velocidade de propagação do vírus preocupa as autoridades máximas em todos os países do mundo. Ao se espalhar, a doença foi mostrando preocupação aos órgãos de saúde que imediatamente definiram protocolos dos mais diversos para conter a propagação e a disseminação do vírus: protocolos de higiene, distanciamento social, isolamento e lockdown (JOYE; MOREIRA; ROCHA, 2020). Nesse contexto as discussões sobre educação nunca estiveram tão em alta, enquanto preocupação geral da sociedade mundial. Assim, a Educação a Distância (EaD) e o ensino remoto emergencial (ERE) têm ocupado a cena e recebido maior destaque na área da educação (VALENTE et al., 2020).

Ensino remoto e Educação a Distância (EaD) são algumas das nomenclaturas empregadas nesse contexto de aulas não presenciais. As atividades educacionais para crianças e adolescentes não se configuram um modelo de EaD, uma vez que este modelo caracterizase por atender, em princípio, um perfil adulto de estudantes. Ademais, existe uma legislação específica sobre a $\mathrm{EaD}$ e uma caracterização muito particular que define esta modalidade de ensino. Para autores como Hodgeset al. (2020) e Justin et al. (2020), o termo correto para este momento é "educação remota em caráter emergencial" ao invés de EaD.

O termo remoto se refere apenas à mudança do espaço físico que outrora era presencial e agora, temporariamente, é remoto (digital), termo muito utilizado na área de Tecnologia de Informação (TI) para se referir a não presencialidade (JOYE; MOREIRA; ROCHA, 2020). Nesse sentido, não estaria sendo criado um novo modelo de ensino, ao passo que a produção de atividades nesse formato seria uma maneira de disponibilizar conteúdos e materiais educacionais enquanto durar a pandemia.

Conforme Joye, Moreira e Rocha (2020), o ensino remoto assemelha-se à EaD apenas no que se refere ao uso de uma educação mediada pela tecnologia digital (TD). Os princípios desse novo formato de "educação remota" seguem conforme os da educação presencial. De acordo com Hodges et al. (2020), o professor é responsável por tudo, desde a seleção dos conteúdos, das produções das videoaulas, da utilização e escolhas de plataformas e meios de comunicação alternativos para que possa haver a interação com o aluno.

Podemos afirmar, portanto, que a educação remota é um princípio importante para manter o vínculo entre estudantes, professores e demais profissionais da Educação. A resposta em contrário pode representar o afastamento por muitos meses de estudantes dos espaços escolares (físicos e virtuais), o que pode comprometer a qualidade da educação, possivelmente mais do que a implementação de iniciativas que mantenham tais vínculos, apesar das limitações que venham a conferir (ARRUDA, 2020, p. 266).

Porém, para que o ER de fato aconteça é necessário que o estudante tenha acesso à internet e às tecnologias digitais. Porém, segundo Dias e Pinto (2020), muitos brasileiros não têm acesso a computadores, celulares ou à internet de qualidade. Nesse sentido, alertam Joye, Moreira e Rocha (2020), para o grande risco de se aumentar a desigualdade social já existente no Brasil, entre aqueles que possuem condições financeiras de acessar uma aula online com internet de qualidade, e aqueles que sequer possuem a condição básica em termos de alimentação. Reitera-se que a LDB 9394/96, em seu artigo 3, menciona que o estado deve garantir igualdade de condições de acesso para todos.

A falta de acesso às TD e a internet de qualidade é um problema que atinge também professores. Para Dias e Pinto (2020), esse é um problema grave que faz parte da vida de 
professores e estudantes, muitos deles localizados nas periferias das grandes cidades ou na zona rural, e que inviabilizam um processo de ensino e aprendizagem de qualidade. No entanto, outros problemas são enfrentados pelos professores, em especial, o domínio das TD como potencializadoras dos processos de ensino e aprendizagem.

Segundo Felcher (2020), os professores argumentam que não receberam formação para o uso das tecnologias digitais, ou que as formações não foram efetivas nesse sentido. Segundo a autora, tanto a formação inicial como a continuada, não são garantia de eficácia, pois a formação inicial, embora aborde as TD em disciplinas específicas e outras que fazem referência às tecnologias digitais na ementa, não é o suficiente. Há que se citar também, que as formações continuadas acontecem, mas muitas delas pensadas e planejadas por alguém que não conhece a realidade e/ou as necessidades do grupo, e que, por fim, não geram as mudanças necessárias.

As formações continuadas para o uso das TD ganharam atenção na corrida pela implementação do ensino remoto. Assim, o estado de Santa Catarina em um curto período de tempo, proporcionou a toda a comunidade escolar a imersão em um mundo de conhecimento e competências, oferecendo um primeiro ciclo de formação pedagógica para atividades escolares não presenciais, 28 "webinars", no período de 02 de abril à 15 de maio de 2020 (SILVA; PETRY; UGGIONI, 2020). Espera-se que as formações possibilitem aos professores o uso das tecnologias digitais como ferramentas potencializadoras da aprendizagem e, não simplesmente, para levar ao estudante o ensino no seu formato tradicional.

Para Costa (2013), o potencial inovador das TD está no professor reconhecer o que essas tecnologias podem fazer de diferente no sentido pedagógico da sala de aula, em relação a outras formas de ensinar. Para Papert (2005), não faz sentido utilizá-las para o mesmo tipo de tarefas que os alunos fariam, quando utilizam meios tradicionais. Nesse sentido, de acordo com Costa (2013) e Sousa (2017), professores e estudantes ainda não compreendem o uso em potencial das TD, mesmo que essas sejam consideradas importantes e fundamentais na educação do século XXI.

Afinal, antes da pandemia do Covid-19 as escolas tinham relações distintas com as TD. Inclusive, segundo Pimentel e Feitoza (2017), estados brasileiros adotavam medidas para que as mesmas não entrassem no ambiente escolar. Ademais, segundo Santos Júnior e Monteiro (2020), as tecnologias digitais também eram acusadas de tirar o sujeito do convívio social. Porém, de acordo com os mesmos autores, em momento de pandemia, elas têm sido cada vez mais utilizadas e pensadas para o benefício coletivo e, em se tratando de educação, elas se apresentam como favoráveis para a mediação, possibilitando a interação de alunos e professores e, assim, dando prosseguimento nos processos de ensino e aprendizagem.

Entretanto, dadas as inúmeras dificuldades encontradas, observamos que as respostas educacionais por meio das tecnologias demonstraram importantes iniciativas no sentido de considerar a excepcionalidade do momento e desconstruir possíveis imobilismos que pudessem comprometer a importância da educação na vida das famílias (ARRUDA, 2020, p. 264).

Porém, a realidade tem sido excessivamente distinta, enquanto há estudantes que têm aula síncrona, com uso de metodologias ativas, material e tecnologia de qualidade, há também, aqueles que recebem apenas o material impresso, sem a possibilidade de interagir com colegas e professores e também esclarecer suas dúvidas. Desse modo, segundo Arruda (2020) é irreversível o impacto causado à educação na China e acredita-se que no Brasil 
também será. Nesse sentido, a UNESCO salienta que a queda na aprendizagem poderá alastrar-se por mais de uma década se não forem criadas políticas públicas que invistam em melhorias de infraestrutura, tecnologias, formação, metodologias e salários, além do reforço da merenda, melhor aproveitamento do tempo, tutoria fora do horário usual das aulas e material adicional, quando possível (UNESCO, 2020).

É urgente a necessidade de criação de políticas e investimentos, como cita a UNESCO, na tentativa de minimizar os efeitos da pandemia na Educação, em um país como o Brasil, que já tem tamanha desigualdade social e educacional. Em especial faz-se referência às TD sem detrimento às outras, tendo em vista que, "[...] não é possível pensar em uma educação que prescinda das TDIC, devido às possibilidades futuras de novas pandemias ou retorno desta e devido à necessidade da escola apropriar-se das produções tecnológicas contemporâneas" (ARRUDA, 2020, p. 265).

\section{Metodologia}

A metodologia adotada nesta pesquisa foi predominantemente qualitativa, considerando que trata da interpretação das realidades sociais (BAUER; GASKELL, 2017), ou seja, visa compreender certos fenômenos através dos dados produzidos. Esses dados foram provenientes de um questionário, que segundo Gil (2012), é uma técnica de investigação composta por um conjunto de questões que são submetidas às pessoas com propósito de obter informações sobre determinado tema. Desse modo, o tema aqui investigado foi o estágio curricular supervisionado no ensino remoto e, para isso, foi utilizado como instrumento para produção de dados, um questionário composto de oito (8) questões abertas, representado no quadro 1.

Quadro 1-Questões do formulário

1) Quando você soube da possibilidade de fazer o estágio no Ensino Remoto, qual foi a sua reação?

2) Você pensou em desistir do estágio no Ensino Remoto? Sim ou não? Justifica.

3) Agora que você realizou o estágio no Ensino Remoto como você o avalia?

4) Quais as facilidades encontradas neste estágio que aconteceu no Ensino Remoto?

5) Quais as dificuldades encontradas neste estágio que aconteceu no Ensino Remoto?

6) O que você aprendeu com a realização deste estágio?

7) Qual a importância das tecnologias digitais para o Ensino Remoto?

8) Quais tecnologias digitais você utilizou para desenvolver o estágio no Ensino Remoto?

Fonte: Autores (2020)

O questionário foi disponibilizado no Google Forms e respondido por três (13) acadêmicos do Curso de Licenciatura em Matemática a Distância de uma Universidade Pública Federal do Sul do Rio Grande do Sul. Os estagiários são provenientes de dois polos diferentes, os quais representam algumas das localidades atendidas pelo CLMD. Eles foram identificados no texto com número, conforme a ordem que foram respondendo o questionário. Os 
acadêmicos estavam em fase de conclusão do curso, sendo que, a maioria, teria se formado em 2020/1, caso não houvesse a pandemia. Apesar de serem oriundos de polos diferentes, o estágio remoto foi realizado no segundo semestre de 2020, no Ensino Médio, em escolas estaduais em um mesmo município do sul do Rio Grande do Sul.

Para analisar os dados produzidos foi empregada a análise de conteúdo. Essa é uma técnica metodológica que pode ser aplicada a diversos discursos e formas de comunicação (BARDIN, 2009). O pesquisador realiza investigações para compreender as características, modelos ou estruturas que estão por trás dos fragmentos em análise. Cabe a ele entender o sentido da comunicação, bem como buscar outra significação, outra mensagem no contexto dos dados em análise.

Ainda, segundo Bardin (2009), a análise de conteúdo prevê três fases fundamentais, a saber: (1) pré-análise; (2) exploração do material (3) e tratamento dos resultados (inferência) e a interpretação. Nessa investigação, a pré-análise consistiu em um primeiro contato com o material, ou seja, uma leitura flutuante das respostas dos acadêmicos; na segunda fase, exploração do material, foram escolhidas as unidades de codificação, as quais são utilizadas com vistas a organizar os dados brutos e criar categorias de análise. Nesta fase as categorias identificadas foram concepções e percepções, sendo que em ambas, destaca-se aspectos positivos e negativos expostos pelos participantes da pesquisa.

Por último, na terceira fase, buscou-se tornar significativo e válido o material produzido, dando sentido ao que está por trás das respostas fornecidas. Para tal, novamente recorreu-se aos teóricos com o objetivo de dialogar com o material produzido e assim apresentar os resultados e discussões.

\section{Resultados e discussões}

Os dados produzidos através dos questionários foram analisados e apresentados de modo a ressaltar as concepções e as percepções dos estagiários tendo em vista a realização do estágio remoto. As concepções e as percepções informam a maneira como as pessoas percebem, avaliam e reagem com relação a um determinado fenômeno pesquisado. Isso possibilita a construção de conceitos envolvidos em uma pesquisa educacional, por exemplo.

\subsection{Concepções}

Ainda que se tenha apenas uma expectativa sobre a formação de conceitos, uma representação de ideias baseadas em características comuns a determinados fenômenos (MATOS; JARDILINO, 2016), as concepções dos estagiários sobre o estágio no ensino remoto, demonstraram uma expectativa nada boa. A maioria deles (oito) respondeu que teve uma reação negativa, descrita através de sentimentos como: decepção, insegurança, susto, receio e ansiedade. A resposta do estagiário 1 reforça esse posicionamento:

Confesso que fiquei decepcionada com a decisão da coordenação do curso. Em primeiro momento pensei em desistir, pois pensava que precisava ter a experiência de realizar esse estágio de forma presencial, ter essa vivência para minha carreira profissional em segundo momento colocando as ideias no lugar optei por dar seguimento a prática do meu estágio assumindo esse compromisso.

(Estagiário 1, 2020). 
Esse registro, além de mostrar a reação do estagiário, evidencia a ideia de desistir do estágio a ser desenvolvido nesse formato. Além deste estagiário, outros quatro também cogitaram a ideia de desistência, trazendo as seguintes justificativas:

[...] ]uma modalidade nova e não saber como seria me assustou.

(Estagiário 7, 2020).

[...]pensei que não iria ter equipamentos necessários para produzir aulas assíncronas, mas, consegui emprestado.

(Estagiário 9, 2020).

Ainda trazendo as concepções dos estagiários, destaca-se que um deles demonstrou uma reação de surpresa com a decisão:

[...] fiquei surpreso, pois mesmo considerando uma boa possibilidade, não esperava que fosse flexibilizada a prática.

(Estagiário 13, 2020).

Os demais estagiários (totalizando oito) descreveram reações positivas em relação à retomada a disciplina de estágio, apontando sentimentos de alívio, felicidade e tranquilidade, os quais puderam ser percebidos no registro do estagiário 3 :

O retorno das atividades escolares de maneira regular parece não ter uma data próxima para ocorrer, cheguei a pensar que não seria possível concluir o curso por conta do mesmo ter uma data limite de cinco anos para ser finalizado, imagine só, mais de quatro anos que basicamente teriam sido desperdiçados sem a possibilidade de conclusão do curso. Foi, como relatei acima, um grande alívio.

(Estagiário 3, 2020).

Se cinco estudantes mencionaram a ideia de desistir do estágio nesse formato, oito deles, mesmo reconhecendo os desafios a serem enfrentados, não pensaram nessa possibilidade. Segundo o estagiário 3, o estágio no ensino remoto foi uma grande oportunidade para concluir o curso em tempo hábil, visto que, por inúmeras vezes, ficou com receio de adiar o sonho de concluir a Licenciatura. Ainda, segundo o estagiário 4:

Existem desafios, sim, mas o importante é encará-los com responsabilidade, determinação e principalmente dedicação ao que nos propomos realizar.

(Estagiário 4, 2020).

\subsection{Percepções}

Tendo em vista o ato de perceber e aprender por meio dos sentidos e impressões, após a realização do estágio no ensino remoto, a percepção de dois estagiários demonstrou que a experiência foi decepcionante, pela própria circunstância de não estar e não poder atuar presencialmente junto aos estudantes e também pela pouca participação dos mesmos. 0 estagiário 7 mencionou o seu esforço para a produção de materiais que contribuíssem para a aprendizagem dos estudantes: 
De maneira geral, foi uma experiência um pouco decepcionante, devido a baixa interação dos estudantes ao longo do período de estágio. Me esforcei bastante, produzi um considerável número de videoaulas (fora outros materiais) visando assim contribuir com a aprendizagem dos estudantes, esperava no mínimo uma maior participação dos mesmos durante as atividades propostas.

(Estagiário 7, 2020).

A pouca participação dos estudantes é citada mais de uma vez por Feitosa et al. (2020). Segundo os autores, os estudantes mencionaram que embora houvesse esforços no sentido de suprir as necessidades apresentadas pelo ER, foi possível perceber carências com relação a interação, pois alguns sentiram-se mais inibidos em participar e tirar dúvidas, além da questão da concentração, que é afetada pelo ambiente em que está inserido. Reforçando, outro estudante mencionou que é bastante complicado se manter centrado tantas horas na tela, o que ocasionou a falta de estímulo (FEITOSA et al., 2020).

Os demais estagiários apresentaram percepções bastante positivas a respeito do estágio no ensino remoto, descrevendo a experiência como incrível, produtiva e importante. O estagiário 8 salientou que muitas aprendizagens foram construídas e que serão levadas para a vida profissional, em especial sobre as TD:

Foi todo um desafio, aprender novas tecnologias, gravar vídeo aulas, aulas no Google Meet, disponibilizar o WhatsApp pessoal para esclarecimentos de dúvidas, todo um aprendizado, que vou levar para a futura profissão. É um incentivo a continuar estudando e aprendendo. Claro que é bem diferente do presencial e sempre ficamos com a incerteza de estar no caminho correto, mas faz parte do aprendizado.

(Estagiário 8, 2020).

Em especial, destaca-se as concepções e percepções do estagiário 1: esse estagiário conforme já mencionado anteriormente, sentiu-se decepcionado com a possibilidade de estagiar no ensino remoto, apresentando, portanto, uma concepção prévia não favorável ao estágio. Porém, posteriormente, descreveu a experiência de forma positiva, destacando-a como maravilhosa. A justificativa para essa percepção foi que os estudantes:

[...] que participaram demonstraram muita vontade de aprender, e quando realizei a web aula por um momento achei q não teria nenhum participante e pelo contrário tive vários e isso foi maravilhoso perceber que mesmo eles quietinhos eles têm vontade de aprender. (Estagiário 1 , 2020).

O depoimento desse estagiário coaduna com a ideia de arriscar, de enfrentar os desafios e estar aberto para aprender, frente às diversas circunstâncias que a realidade impõe. Valente et al. (2020), ressalta a importância de uma prática docente centrada cada vez mais na lógica do "aprender a aprender", considerando a criatividade e a pesquisa, num contexto educacional de grandes mudanças, no Brasil e no mundo. Para o autor, talvez, em nenhum outro momento de nossa história foi tão necessária a ação criativa dos educadores. Afinal, no formato de ensino remoto não existem receitas prontas ou modelos a serem seguidos, o que faz com que os professores tenham que construir seus próprios projetos.

No que diz respeito às facilidades encontradas neste estágio, dois acadêmicos citaram que não encontraram nenhuma. Os demais apontaram com maior ocorrência duas 
facilidades: 1) não precisar se locomover para ministrar a aula, podendo realizar o trabalho de suas casas: facilidade encontrada no texto de Feitosa et al. (2020), que foi citada pelos professores e também pelos estudantes participantes da pesquisa; 2) referente às TD: alguns deles (quatro) apontaram que se sentiram confortáveis em utilizá-las, visto que, conheciam as ferramentas adotadas (plataforma Classroom, GoogleMeet, Power Point, redes sociais Facebook e WhatsApp). Também é importante salientar na resposta de um dos estagiários, que foi mais fácil de lidar com a turma sem as possíveis interrupções corriqueiras, que costumam acontecer, por parte dos alunos, durantes as aulas presenciais.

Quando os estagiários mencionaram as facilidades referentes às TD, citaram que conhecê-las contribuiu positivamente para a utilização nas práticas de ensino, salientando como positiva a possibilidade de regravar as videoaulas quando foi possível perceber algum erro, bem como, programar a plataforma para a postagem no horário determinado pela escola. Nesse sentido, o estagiário 7 afirmou que sua maior facilidade:

[...]foi em já conhecer as tecnologias em saber lidar no Google Meet, Power point, word, pois acredita que essa deva ter sido a dificuldade de muitos professores.

(Estagiário 7, 2020).

O não conhecimento das TD como meio para a aprendizagem traz ao professor desafios ainda maiores quando se trata do ensino remoto. Nesse cenário, Feitosa et al. (2020), ressalta que o ensino remoto foi algo inesperado. Professores que não estão familiarizados com web conferências e videoaulas podem apresentar resistências para aceitarem a nova forma de ensinar e aprender. Porém, se para alguns professores aprender e adaptar-se a essa nova fase tem sido uma tarefa árdua, a grande maioria dos alunos domina com facilidade o uso de tecnologias digitais (VALENTE et al., 2020).

Se o uso das TD foi mencionado por quatro estagiários, como uma das facilidades encontradas no ensino remoto, para outros seis, usar as tecnologias digitais foi motivo de dificuldades. Dentre elas destacam-se:

Dificuldades houve muitas, a princípio encontrar um programa para poder gravar as aulas. Estudar como utilizar os programas e ver a melhor opção, para isso se levou muito tempo. (Estagiário 9, 2020).

Sistemas classroom totalmente diferente do moodle, encontrei muita dificuldade.

(Estagiário 11, 2020).

As dificuldades anteriormente mencionadas, também são encontradas em Feitosa et al. (2020), o que fez com que os professores dedicassem um tempo maior empregado para a realização do ensino remoto, exigindo o trabalho, inclusive, nos finais de semana. Para Joye, Moreira e Rocha (2020), a pandemia expôs um problema antigo que é a falta de formação docente para o uso das TD. Frente a essa necessidade, os professores partem para o improviso, usando redes sociais, produzindo videoaulas e postando no YouTube, enviando atividades previamente selecionadas dos livros didáticos aos grupos de WhatsApp, fazendo videoconferências, utilizando aplicativos como o Google Meet ou o Zoom Meeting, entre outros (JOYE; MOREIRA; ROCHA, 2020).

Ainda, quatro estagiários citaram que elaborar o planejamento foi uma dificuldade. Conforme estagiário 4: 
Elaborar os planos de aula sem conhecer efetivamente o Ensino Remoto foi um dos grandes desafios, bem como adaptar os conteúdos e atividades nos períodos de aula e avaliar as atividades dos discentes.

(Estagiário 4, 2020).

Três estagiários mencionaram a interação/participação dos estudantes como a maior dificuldade encontrada no ensino remoto. Conforme o estagiário 3:

A baixa participação dos estudantes dificultou bastante um planejamento que tivesse por objetivo colaborar com a aprendizagem dos mesmos.

(Estagiário 3, 2020).

A interação dos alunos, acho que foi minha maior dificuldade, em não conseguir fazer que mais alunos participassem das aulas.

(Estagiário 6, 2020).

Na sequência, as TD aparecem como aprendizagens construídas no período de estágio no ensino remoto, por seis estagiários. Entre tais registros destaca-se:

Que as tecnologias são os métodos de ensino que devem caminhar lado a lado com o professor, pois se a maioria já adotasse algumas práticas durante suas aulas, hoje talvez teria sido mais fácil a interação do aluno nas aulas remotas.

(Estagiário 2, 2020).

Utilizar programas para gravar vídeo aulas. Utilizar o Google Meet. Aperfeiçoar a utilização de alguma ferramenta como o GeoGebra por exemplo.

(Estagiário 6, 2020).

Aprendi que o uso da tecnologia favorece a interação entre alunos e professor e percebi que jogos, animações e desafios despertam a curiosidade dos alunos.

(Estagiário 12, 2020).

Embora os registros acima expressem percepções que coadunam com a utilização em potencial da tecnologia digital no ensino e aprendizagem, muitos professores não compartilham desse pensamento. E em tempos de ensino remoto, utilizam as TD apenas pela necessidade que a conjuntura impõe. Nesse âmbito é preciso (re)pensar a formação de professores, a qual segundo Valente et al. (2020), deve gerar uma mobilização para adesão voluntária e, posteriormente, levá-los a deslocarem o foco de suas ações pedagógicas da tecnologia em si mesma para o alvo, focalizado na aprendizagem que fundamenta e estrutura seu fazer docente, visto que, "[...] são os objetivos formativos que devem orientar a escolha das tecnologias e não o contrário" (VALENTE et al., 2020).

Ainda, em se tratando das TD, de maneira unânime, os acadêmicos citaram que as tecnologias digitais são fundamentais para o ensino remoto, e que sem elas, não seria viável esse formato de ensino e aprendizagem:

As tecnologias digitais são de extrema relevância no Ensino Remoto, pois é através delas que ocorre o processo de ensino e aprendizagem, a interação e a comunicação entre alunos $e$ professor.

(Estagiário 4, 2020).

Com as tecnologias digitais foi possivel chegar a uma parte dos alunos. Assim mesmo acredito que houve certa discriminação e separação dos que tem acesso a internet dos que não tem. 
(Estagiário 8, 2020).

Com a suspensão das aulas devido a pandemia o ensino remoto está totalmente sendo reproduzido através da tecnologia, acabou tornado o único recurso utilizado para os alunos não perderem o ano letivo.

(Estagiário 10, 2020).

O estagiário 8 chama atenção para a desigualdade social que, em tempos de pandemia, ficou ainda mais aguçada. Nesse sentido, a internet, imprescindível para o ensino remoto, não chega a todos os lares ou chega de maneira precária. Segundo Joye, Moreira e Rocha (2020), o acesso à Internet, principalmente no interior do Brasil, é bem deficitário. Ainda, os autores trazem à tona outro problema que é o acesso à internet via smartphone. Uma pesquisa recente aponta que $97 \%$ dos usuários de telefone celular (smartphone) têm acesso à Internet através desse dispositivo móvel, enquanto que $53 \%$ têm acesso através de um computador de mesa ou um notebook (JOYE; MOREIRA; ROCHA, 2020). Esses dados merecem atenção, pois, mostra que a maioria dos estudantes brasileiros tem o smartphone como equipamento para assistir aulas e realizar algumas tarefas solicitadas, porém, devido ao tamanho da tela, sabe-se que não é o equipamento mais adequado para produzir textos, por exemplo.

Considerando que as TD são essenciais para o ensino remoto, múltiplas são as possibilidades de uso para ensinar Matemática (BORBA; SILVA; GADANIDIS, 2015). Em ordem decrescente são citadas as tecnologias digitais que foram mais utilizadas no ensino remoto pelos estagiários: a Classroom é de maneira unânime citada por todos, visto que, é a plataforma da rede estadual de ensino do Rio Grande do Sul, seguido pelo WhatsApp (8); Videoaula (8); Editor de vídeo (6); Google Meet(5); Celular (5); Notebook (5); Aplicativos (5), Youtube (3); entre outros.

Diante das inúmeras possibilidades oportunizadas pelas tecnologias digitais, destacam-se, segundo Valente et al. (2020), que o mundo é tecnológico e rico em estratégias e ferramentas, por isso, bastante apropriado para realização do ensino remoto e do processo de avaliação dos alunos. No entanto, é preciso tecer considerações a respeito desse uso, visto que, uma aula expositiva de 50 minutos tende a ser cansativa. No ensino remoto isso pode ser ainda menos produtivo, se não pensarmos em estratégias ativas de ensino e de aprendizagem, o que requer mudanças significativas na prática docente (VALENTE et al., 2020)

Além das aprendizagens relacionadas às TD, os estagiários mencionaram também, a necessidade de aprender mais e mais e que há formas diferentes de se dar aula, mas que a dedicação é fundamental para o sucesso do estágio no ensino remoto.

Aprendi que na vida temos muito que aprender, e que a cada obstáculos que conseguimos vencer é uma bagagem que adquirimos.

(Estagiário 2, 2020).

Aprendi que o professor necessita estar preparado para as inúmeras adversidades que podem ocorrer em sua trajetória profissional, estar em constante reflexão e aprimoramento de suas práticas docentes, pois as dificuldades existem e podem ser superadas, mas é necessário muita dedicação e comprometimento para o objetivo principal que é de proporcionar um aprendizado significativo, onde o aluno é o protagonista da construção do seu conhecimento. (Estagiário 4, 2020).

Diante das exigências do ensino e mais especificamente agora do ensino remoto, há de se considerar a formação de um profissional reflexivo, que consiste na capacidade de 
pensamento e reflexão, que o caracteriza como um ser humano criativo e não como mero reprodutor de práticas que lhe são exteriores (ALARCÃO, 2011). A defesa por este tipo de formação está além de um estágio na perspectiva da prática pela prática ou da experiência pela experiência, algo puramente técnico, burocrático, sem a devida problematização e reflexão. É fundamental, "[...] projetos que valorizem a pesquisa, as práticas coletivas, colaborativas e reflexivas, tão favoráveis ao desenvolvimento profissional, não apenas dos futuros professores, como também dos demais atores envolvidos nesse processo de formação" (SAKAl; PEREIRA, 2017, p. 114).

A formação de um profissional reflexivo vai ao encontro do exposto por Valente et al. (2020), quando reforça que o momento vivido na educação é um desafio que a realidade impõe, porém é necessário "aprender a aprender", em especial sobre a utilização das tecnologias como parceira para a efetivação da prática docente. Porém, segundo Dias e Pinto (2020) é urgente que o estado se faça presente, investindo em políticas públicas que garantam um financiamento adequado da Educação, onde se faça um uso inteligente das tecnologias disponíveis, priorizando os mais vulneráveis e protegendo educadores e alunos.

\section{Considerações finais}

É evidente que o ensino remoto é permeado de problemas e dificuldades, sob a ótica da gestão escolar, professores e estudantes e comunidade de um modo geral. No entanto, esse formato de ensino é essencial frente ao momento de insegurança e incerteza que abalou a sociedade. É o ensino remoto, mesmo com suas deficiências, que vem buscando amenizar os impactos irreversíveis da pandemia na Educação, possibilitando manter o vínculo entre estudantes e escolas, e também, dando continuidade no processo de ensino e aprendizagem.

Nesse cenário de ensino remoto, os estágios curriculares foram desenvolvidos, trazendo ainda mais desafios que os já esperados pelos professores em formação inicial. Porém, considerando os obstáculos e o grau de dificuldade imposto, conforme mencionam os estagiários, a experiência foi produtiva e de grandes aprendizagens. O que vem afirmar que oferecer o estágio curricular nesse formato foi válido, tanto em termos cognitivos, bem como no sentido de dar prosseguimento a formação dos professores, afinal, concluir um curso superior é o sonho de inúmeras pessoas.

As tecnologias digitais tão importantes na atualidade são indispensáveis no ensino remoto, porém, deseja-se que as mesmas não sejam utilizadas apenas para transportar o ensino tradicional até o estudante, mas sim, como ferramentas potencializadoras dos processos de ensino e aprendizagem, reconfigurando os espaços e possibilitando novas representações da realidade. Para tal é urgente que os cursos de formação de professores sejam (re)pensados nesse sentido, bem como as formações continuadas, afinal, o futuro da educação é incerto, mas não pode parar.

\section{Referências}

ALARCÃO, Isabel. Professores reflexivos em uma escola reflexiva. São Paulo: Cortez, 2011.

ARAÚJO, Osmar Hélio Alves. O estágio como práxis, a pedagogia e a didática: que relação é essa? Revista Eletrônica de Educação, v. 14, p. 1-15, 2020. 
ARRUDA, Eucidio Pimenta. Educação remota emergencial: elementos para políticas públicas na educação brasileira em tempos de Covid-19. Em Rede - Revista De Educação a Distância, v. 7, n. 1, p. 257-275, 2020.

BARDIN, Laurence. Análise de conteúdo. Lisboa: Edições 70, 2009.

BAUER, Martin W.; GASKELL, George. Pesquisa qualitativa com texto, imagem e som: um manual prático. Petrópolis: Vozes, 2017.

BORBA, Marcelo de Carvalho; SILVA, Ricardo Scucuglia Rodrigues da; GADANIDIS, George. Fases das tecnologias digitais em Educação Matemática. Belo Horizonte: Autêntica, 2015.

BRASIL. LEI № 9.394/1996. Diretrizes e Bases da Educação Nacional. Brasília, 1996.

BRASIL. RESOLUÇÃO CNE/CP № 1/2002. Diretrizes Curriculares Nacionais para a Formação de Professores da Educação Básica. Brasília, 2002.

BRASIL. Parecer CNE/CP no 5/2020. Disponível em:

http://portal.mec.gov.br/index.php?option=com_docman\&view=download\&alias=145011pcp005-20\&category_slug=marco-2020-pdf\&Itemid=30192. Acesso em:25 out. 2020.

BRASIL. Ministério da Educação. Conselho Nacional de Educação. Resolução CNE/CP 2, de 12 de julho de 2015. Brasília, DF, 2015. Disponível em:

http://portal.mec.gov.br/docman/agosto-2017-pdf/70431-res-cne-cp-002-03072015pdf/file. Acesso em: 05 nov. 2020

COSTA, Fernando Albuquerque. O potencial transformador das TIC e a formação de professores e educadores. In: ALMEIDA, Maria Elizabeth Bianconcini de; DIAS, Paulo; SILVA, Bento Duarte da (Org.). Cenários de inovação para a educação na sociedade digital. São Paulo: Edições Loyola, 2013. p. 47-74.

CYRINO, Márcia Cristina Costa Trindade; PASSERINI, Gislaine Alexandre. Reflexões sobre o estágio supervisionado do curso de Licenciatura em Matemática da Universidade Estadual de Londrina. In: CAINELLI, Marlene Rosa; SILVA, Ileizi Luciana Fiorelli (Orgs.). O estágio na licenciatura: a formação de professores e a experiência interdisciplinar na Universidade Estadual de Londrina. 1ed. Londrina: UEL/Prodocencia/Midiograf, 2009. p. 125-144.

DIAS, Érika; PINTO, Fátima Cunha Ferreira. A Educação e a Covid-19. Ensaio: aval.pol.públ.Educ., Rio de Janeiro, v. 28, n. 108, p. 545-554, Sept. 2020.

FEITOSA, Murilo Carvalho et al. Ensino Remoto: O que Pensam os Alunos e Professores? In: CONGRESSO SOBRE TECNOLOGIAS NA EDUCAÇÃO (CTRL+E), 5., 2020, Evento Online. Anais[...]. Porto Alegre: Sociedade Brasileira de Computação, 2020. p. 60-68. Disponível em: https://doi.org/10.5753/ctrle.2020.11383. Acesso em: 25 out. 2020. 
FELCHER, Carla Denize Ott; FOLMER, Vanderlei. Ciberformação com professores de matemática: concepções e percepções frente ao uso do código QR. Educação Matemática em Revista - RS - ANO 20 - 2019 - número 20 - v.1 - p. 62 - 71.

FELCHER, Carla Denize Ott. Tecnologias digitais: percepções dos professores de matemática no contexto do desenvolvimento profissional docente. Tese de Doutorado. Programa Educação em Ciências: Química da Vida e Saúde. UFRGS. 2020.

FIORENTINI, Dario; CASTRO, Franciana Carneiro de. Tornando-se professor de matemática: o caso de Allan em prática de ensino e estágio supervisionado. In: FIORENTINI, Dario (Org.). Formação de professores de Matemática: explorando novos caminhos com outros olhares. Campinas: Mercado das Letras, 2003.

Gil, Antonio Carlos. Métodos e Técnicas de pesquisa social. São Paulo: Altas, 2012.

HODGES, Charles et al. The Difference Between Emergency Remote Teaching and Online Learning. Educause Review, [S. I.], março, 2020.

INSTITUTO NACIONAL ESTUDOS E PESQUISAS. Falta de professores preocupa especialistas. In: MINISTÉRIO da Educação, [S. I.], 2008. Disponível em: http://portal.mec.gov.br/sesusecretaria-de-educacao-superior?task=view\&id=9885. Acesso em: 25 nov. 2020.

JOYE, Cassandra Ribeiro; MOREIRA, Marília Maia; ROCHA, Sinara Socorro Duarte. Distance Education or Emergency Remote Educational Activity: in search of themissing link of school education in times of COVID-19. Research, Society and Development, v. 9, n. 7, p. 1-29, 2020.

$\mathrm{REICH}$, Justin et al. Remote learning guidance from state education agencies during the COVID-19 pandemic: a first look. EdArXiv, [S. I.], 2020.

LIMA, Maria Socorro Lucena; PIMENTA, Selma Garrido; Estágio e docência: diferentes concepções. Revista Poíesis, v. 3, n. 3, p.5-24, 2006. Disponível em: https://doi.org/10.5216/rpp.v3i3e4.10542. Acesso em: 09 out. 2019.

MATOS, Daniel Abud Seabra; JARDILINO, José Rubens Lima. Os conceitos de concepção, percepção, representação e crença no campo educacional: similaridades, diferenças e implicações para a pesquisa. Educação \& Formação, Fortaleza, v. 1, n. 3, p. 20-31, set./dez., 2016.

PAPERT, Seymour. Techology in Schools: To support the System of Render it Obsolete? Educational Technology, [S. I.], 2005.

PIMENTEL, Fernando Silvio Cavalcante; FEITOZA, Maria Janaína dos Santos. O uso da tecnologia móvel (celular) no contexto educacional. Revista Educação a Distância e Práticas Educativas Comunicacionais e Interculturais, São Cristóvão, v. 17, n. 03, p. 129-139, 2017. 
SANTOS JÚNIOR, Verissimo Barros dos; MONTEIRO, Jean Carlos da Silva. Educação e covid19: as tecnologias digitais mediando a aprendizagem em tempos de pandemia. Revista Encantar-Educação, Cultura e Sociedade, v. 2, p. 1-15, 2020.

SAKAI, Edinalva da Cruz Teixeira; PEREIRA, Patrícia Sandalo. Dialogando com as modalidades de práticas de estágio supervisionado em Matemática. Revista Paranaense de educação Matemática, Campo Mourão, v.6, n.10, p.90-117,jan.-jun. 2017.

SILVA, Luiz Alessandro da; PETRY, Zaida Jeronimo Rabello; UGGIONI, Natalino. Desafios da educação em tempos de pandemia: como conectar professores desconectados, relato da prática do estado de Santa Catarina. In: PALÚ, Janete; SCHÜTZ, Jenerton Arlan; MAYER. Leandro. Desafios da educação em tempos de pandemia. Cruz Alta: Ilustração, 2020.

SOUSA, Daniel Keglis. Utilização e integração das Tecnologias Digitais de Informação e Comunicação nos processos de ensino: um estudo a partir da capacitação do PROMIDIAS.2017. 194 p. Dissertação de Mestrado. UFPel, 2017.

SOUZA, Ester Maria de Figueiredo; FERREIRA, Lúcia Gracia. Ensino remoto emergencial e o estágio supervisionado nos cursos de licenciatura no cenário da Pandemia COVID 19. Revista Tempos E Espaços Em Educação, v. 13, n. 32, p. 1-19, 2020.

UNESCO. A Comissão Futuros da Educação da Unesco apela ao planejamento antecipado contra o aumento das desigualdades após a COVID-19. Paris: Unesco, 16 abr. 2020. Disponível em: https://pt.unesco.org/news/comissao-futuros-da-educacao-da-unescoapela-ao-planejamento-antecipado-o-aumento-das. Acesso em: 2 nov. 2020.

VALENTE, Geilsa Soraia Cavalcanti et al. O ensino remoto frente às exigências do contexto de pandemia: Reflexões sobre a prática docente. Research, Society and Development, v. 9, n. 9, 2020.

VALVERDE, Liliane Pires. A Experiência do Estágio Supervisionado para alunas de um curso Normal: Algumas contribuições para a Formação de Educadores. 2005. Dissertação (Mestrado em Ensino, Filosofia e História das Ciências). Universidade Federal da Bahia. Salvador, 2005. 